\title{
A FORMAÇÃO DE PROFESSORES NO BRASIL E SUA MECÂNICA DE SUBJETIVAÇÃO
}

\author{
Guilherme Corrêa $^{1}$ \\ Fernanda Monteiro Rigue ${ }^{2}$ \\ Tascieli Feltrin ${ }^{3}$
}

\section{Introdução}

Com base na publicação da Lei $n^{\circ}$ 9.394, de dezembro de 1996, é estabelecida a obrigatoriedade do Ensino Médio a todo brasileiro, juntamente com o currículo mínimo, no qual a Química insere-se ao montante de disciplinas da grade curricular. Antes dessa ação legal, diversos foram os movimentos e investidas para que isso fosse possível. As condições de possibilidades internas e externas culminaram para a consolidação e permanência da Química em um sistema nacional de escolarização que se mantém obrigatório até hoje e produz efeitos diretos na vida de cada indivíduo. Ir à escola a partir dos cinco anos de idade, andar em fileira, assistir aulas, manter o silêncio e a ordem, resolver exercícios, permanecer em atenção, realizar provas frequentes, são exigências comuns e naturalizadas nas sessões educacionais promovidas pela escola.

Para entender a operação de forças visando a consolidação de um sistema nacional de educação, este estudo realizou um panorama Genealógico (FOUCAULT, 1979) sobre o percurso de instauração da Química como disciplina no Brasil, através dos seguintes períodos: Colonial e Imperial; o Estado Novo e o "escolanovismo" até a Ditadura Militar. A partir dessa linha é possível apresentar o jogo de forças que configura os cursos de Formação de Professores no Brasil, na contemporaneidade. Para isso esse recurso à história do Ensino de Química é associado ao da ficção como meio para problematizar a terra arrasada da Formação de Professores.

\section{Todos}

A educação no Brasil se institucionaliza através dos ideais de uma Educação pública pelas vias da escolarização. A obrigatoriedade do Ensino Médio foi oficializada em dezembro de 1996, trazendo consigo fortes influências e motivações de cunho político, econômico e militar. No seio do projeto de Educação Pública e do Ensino Médio se faz presente a disciplina de Química.

A emergência do ensino de Química no Brasil constitui uma linha que inicia com pontos esparsos e com poucas articulações entre si, que vão sendo alargados com consideráveis movimentos e forças. Durante a chegada e permanência dos Jesuítas da Companhia de Jesus, pequenos eram os pontos vinculados aos interesses da existência da Química enquanto disciplina. Com a vinda da Família Real para o Brasil, os pontos foram ficando mais próximos e visíveis, em virtude da instalação da sede do antigo reino português no Brasil (após a concorrência econômica e política que o país vinha sofrendo da Inglaterra e da França na Europa); da forte atração e envolvimento do imperador Dom Pedro II pelas Ciências Naturais, principalmente a Química; bem como a instrução que era oferecida aos membros da Família Real para que continuassem desenvolvendo atividades de cunho

\footnotetext{
${ }^{1}$ Professor da Universidade Federal de Santa Maria - UFSM. E-mail: gcarloscorrea@gmail.com.

${ }^{2}$ Universidade Federal de Santa Maria - UFSM. E-mail: fernanda_rigue@ hotmail.com.

${ }^{3}$ Universidade Federal de Santa Maria - UFSM. E-mail: tascifeltrin@gmail.com.
} 
científico, agora no Brasil. Com a vinda de Marquês de Pombal para o Brasil, os pontos começam a ficar mais conectados na medida em que censuram os anseios religiosos dos Jesuítas, e como atualização dos ideais iluministas, servem aos interesses econômicos de ascensão da Corte Portuguesa.

O período Colonial brasileiro (1500-1822) e o período Imperial (1822-1889) foram marcados fortemente por uma série de ações realizadas em solo Português: a Reforma Pombalina (1772) e as reformas ocorridas na Universidade de Coimbra (1772). Essas iniciativas realizadas em Portugal, foram cruciais para as primeiras movimentações no Brasil referentes ao Ensino de Ciências Naturais, tendo em vista a chegada dos portugueses no território brasileiro. A obra intitulada As ciências em Portugal e no Brasil (1772-1822): o texto conflituoso da química, de Márcia Ferraz (1997), foi a principal fonte de dados utilizada para esse período.

A Reforma Pombalina, com seu principal representante, Sebastião José de Carvalho e Melo (Marquês de Pombal), inaugura a prática do Ensino de Ciências vinculada aos interesses econômicos e políticos da Coroa Portuguesa. Operou uma série de Reformas na Universidade de Coimbra, a partir da publicação dos Estatutos que culminariam com o aparecimento do ensino das ditas novas ciências. A motivação para essas modificações esteve relacionada com o humanismo crescente na Europa, bem como com as necessidades de expansão econômica de Portugal. Do mesmo modo, a preocupação com a inserção das Ciências Modernas, fortalecidas pelo movimento Iluminista e a ênfase nas críticas direcionadas aos Jesuítas, dão motivação para que nesse momento os pontos aparentemente dispersos, mostrem sua tendência ao alinhamento.

A vinda do Marquês de Pombal em 1759 para o Brasil, implicou na expulsão das grandes referências em Educação aqui existentes-os padres da Companhia de Jesus, representando um desmantelamento da educação da época. O crescimento das navegações e das descobertas territoriais, moveu o foco das estruturas sociais, das letras e da retórica, para os saberes da Matemática e das Ciências Naturais, provocando fortalecimento das atividades econômicas e mercantis da Colônia. No Brasil, Pombal implementou as Aulas Régias, que encontraram expressão nos documentos oficiais, mas não foram implementadas como prática educacional.

A vinda da Corte Real para o Brasil trouxe consigo a efetivação de alguns Alvarás e Regulamentações, tendo em vista o novo cenário que se instaurava no início do século XIX. Dom João VI foi responsável pela abertura dos portos nacionais (28 de Janeiro de 1808), representando $\mathrm{o}$ interesse em fortalecer as relações internacionais. Assim "a abertura dos portos às nações amigas canalizou para o Brasil uma corrente de imigração, fraca em número, é verdade, mas considerável pelo mérito e pelo saber" (ALMEIDA, 2000, p. 55). Do mesmo modo, ainda no reinado de Dom João VI, houve a primeira tentativa para a institucionalização das Ciências Naturais no Brasil, criando-se o Laboratório de Química no Rio de Janeiro, em 1811 (ALMEIDA, 2000, p. 42), juntamente com a fundação da Academia Militar Real do Rio de Janeiro, no ano de 1810. Buscavase formalizar espaços de cunho científico, visto que na Europa isso já vinha sendo feito com maior intensidade, principalmente pela iniciativa dos Naturalistas.

Em 1817, foi criada na Bahia, uma cadeira de Química, sob a responsabilidade de Sebastião Navarro de Andrade ${ }^{4}$. As instruções para o Curso previam que o professor deveria fazer todas as atividades teóricas e práticas, proporcionando agilidade às operações químicas (FERRAZ, 1997). No mesmo ano "uma comissão de sábios austríacos e bávaros: Mikau, Pohl, Spix, Martius e Raddi, acolhida regiamente por D. João VI, percorreu o Brasil e estudou as riquezas naturais" (ALMEIDA, 2000, p. 49).

\footnotetext{
${ }^{4}$ Atuou como secretário da Faculdade de Filosofia. Estudou Medicina, Filosofia e Matemática.
} 
Com a necessidade de retornar à Portugal, Dom João VI deixou no Brasil seu filho, o Príncipe Regente, conhecido popularmente por Dom Pedro I. Dom Pedro I fundou a "Academia das Belas-artes, nas bases estabelecidas pelo Decreto Real de 25 de novembro de 1820" (ALMEIDA, 2000, p. 56). Porém, suas ações na esfera científica, com ênfase nas Ciências Naturais/Química, foram muito tímidas, quando comparadas às de seu pai.

Mesmo com todo o aparelhamento científico trazido para o Brasil, a propósito da chegada da Família Real, só com Dom Pedro II a Química foi objeto de investimentos mais amplos. Aqui a Química ultrapassa os interesses econômicos e políticos e passa a corresponder aos anseios de uma Química voltada para Educação.

Dom Pedro II, filho de Dom Pedro I e de Leopoldina, teve como tutor José Bonifácio; sua Regência durou entre 1831 e 1889 e, apenas nesse período, foram criados subsídios para o Ensino de Química no país. Por meio de várias viagens investigativas, conheceu personalidades científicas europeias, que foram base para o seu interesse considerável pela pesquisa. Dom Pedro II, além de dedicar seu tempo ao estudo dos horizontes da pesquisa, visitava as escolas existentes na época, buscando conhecê-las em todos os seus aspectos.

A influência dos seus professores, José Bonifácio e Alexandre Vandelli, fez com que o soberano fosse um aluno dedicado aos estudos da Química, sendo quase constante sua presença em aulas, exames, encontros e discussões científicas na Europa. Sua casa ostentava um laboratório de Química, no qual realizava experimentos e estudava obras de químicos da Europa, como Dalton e Laurent (FILGUEIRAS, 1988).

No ano de 1837, criou o Colégio D. Pedro II. A partir do ano de 1856 a Química e a Física começaram a ser ministradas separadamente no colégio. Por meio de uma análise dos livros didáticos dos anos de 1838, 1850 e 1856, pode-se perceber que o colégio de Dom Pedro II utilizava-se de apenas um livro para a abordagem da Física e da Química. O Imperador se preocupava com a educação das filhas, sendo a Princesa Isabel a que mais teve afeição pelos estudos científicos. A publicação de Filgueiras (2004), intitulada: "A Química na Educação da Princesa Isabel”, é fiel ao retratar os estudos da mesma, bem como a insistência de D. Pedro II em torná-la uma apaixonada pela Química. Além do mais, o imperador tinha uma preocupação crescente em contribuir para o desenvolvimento intelectual da filha, visto que esta seria sua possível sucessora no trono.

Com a queda do Império no Brasil em 1889, pode-se considerar que a forma do Ensino de Química, no final desse período, está totalmente relacionada com as ações de Dom Pedro II no Império. Embora existissem pouquíssimos colégios distribuídos pelo solo brasileiro e o Colégio D. Pedro II, por exemplo, seja um dos poucos ainda existentes-, houve uma preocupação considerável, bem como iniciativas de sucesso, para a consolidação da instrução pública, juntamente com o Ensino de Química, embora discreto, nas suas pesquisas científicas individuais e familiares.

Enquanto isso o mundo sofre o impacto da I Guerra Mundial (1914-1918) que, ao seu término, põe em circulação todo um novo aparato científico-tecnológico em que tem destaque a Química, principalmente no que diz respeito ao seu poder de produção de novas e definitivas armas, tais como a dinamite e os gases tóxicos. As Ciências Naturais, a partir daí, se dividem em Física, Química e Biologia. Disciplinas que se tornam importantes e decisivas em tempos de guerra e que, paradoxalmente, renovam as promessas de paz.

Com a ascensão da Era Vargas (1930 a 1945) e do período desenvolvimentista brasileiro (1945 a 1961), o Ensino de Química embrionário é atravessado por diversas iniciativas científicas e tecnológicas, em função da ampliação da produção científica na área das Ciências Naturais e da Medicina. Houve um forte empreendimento do governo para reformular a 
educação vigente no país, por meio de várias reformas ${ }^{5}$. A Reforma de Benjamin Constant ${ }^{6}$, ocorrida em 1890, é um dos exemplos desse empreendimento, a qual esteve empenhada em modificar o Ensino Secundário no país. A inserção de uma disciplina englobando conteúdos de Química e Física Geral no $5^{\circ}$ ano do Ensino Superior foi uma das novidades da Reforma de Benjamin Constant. A Química, enquanto campo de conhecimento, começa a dar os primeiros sinais de sua tendência a se tornar uma ciência discreta. Juntamente com a Física e a Biologia passa, progressivamente, a se diferenciar, uma vez que coexistiam indistintas, no campo conhecido como Ciências Naturais.

No rastro da Reforma Benjamin Constant, com sua ênfase positivista, destaca-se, aqui, a atuação de Francisco Campos, o primeiro Ministro da Educação brasileira, após a Revolução de 30, movido por ideais explicitamente fascistas ${ }^{7}$,

Foi responsável pela primeira reforma educacional de caráter nacional que se estendia ao ensino secundário, comercial e superior [...] Seu trabalho no Ministério representou a celebração de um pacto entre a Igreja, o governo de Getúlio Vargas e a simpatia deles todos ao fascismo europeu (CORRÊA, 2006, p. 55-56).

A preocupação de Francisco Campos, juntamente com outros interessados, esteve sempre direcionada para,

Compor o coro dos que viam a estatização como solução para o problema das profundas desigualdades sociais, para manter os privilégios da burguesia estabelecida, para conquistar lugar junto à essa burguesia, para instalar grupos industriais estrangeiros (CORRÊA, 2006, p. 58).

Conforme o que nos diz Lauro de Oliveira Lima (LIMA, 1969, p. 120), Francisco Campos “depois de uma revolução vitoriosa, é uma espécie de Benjamin Constante, que elaborou seu projeto de reforma educacional em circunstâncias semelhantes às do ideólogo do positivismo (p. 120)". Uma nova ordem foi articulada como estratégia para desenvolver uma cultura de nacionalização. A nacionalização era uma via para dar coerência às iniciativas de formação de cidadãos úteis que permitiriam a manutenção do Estado, "Campos percebia a educação nacional como o mais importante apoio para a manutenção do governo, uma questão política, sem dúvida, mas também de administração estatal" (CORRÊA, 2006, p. 150). Por isso, as escolas tiveram destaque na ênfase ao espírito de nacionalização e constituíram a base para a adequação do povo ao sistema de governo vigente.

A escola integra-se no sentido orgânico e construtivo da coletividade, não se limitando ao simples fornecimento de conceitos e noções, mas abrangendo a

\footnotetext{
${ }^{5}$ Dentre elas pode-se destacar: Reforma de Benjamin Constant (1980); Reforma Código Epitácio Pessoa (1901), que levou o nome do principal idealizador, o qual posteriormente tornou-se Presidente do país, a ênfase desse código esteve atrelado ao fortalecimento de questões de cunho literário na Educação/Ensino Secundário; Reforma Rivadávia Correa (1911), que popularmente ficou conhecida por desoficializar o ensino no Brasil; Reforma Carlos Maximiliano (1915), a qual se preocupou em qualificar o Ensino Secundário, devido à falta de preparo dos alunos que ingressavam na Educação/Ensino Superior; Reforma João Luis Alves (1925), a qual foi crucial para a consolidação e regulamentação da Educação/Ensino secundário brasileiro.

${ }^{6}$ Militar, com forte pendor positivista, o qual foi presidente do primeiro ministério (Ministério da Instrução Pública e correios e telégrafos), encarregado de delinear a Educação pública.

${ }^{7}$ Segundo Corrêa (2006, p.56), "Entusiasta do regime totalitário, Campos elaborou a Constituição de 1937, quando do golpe militar que instituiu o Estado Novo". Sobre a relação de Francisco Campos e Fascismo cf. CAMPOS, 1940.
} 
formação dos novos cidadãos, de acordo com os verdadeiros interesses nacionais. (...) $\mathrm{O}$ ensino é, assim, um instrumento em ação para garantir a continuidade da Pátria e dos conceitos cívicos e morais que nela se incorporam (CAMPOS, 1940, p. 65-66).

Se, com Francisco Campos já se sabia a finalidade de uma escola nacional e sua relação com um povo a ser formado, segundo os interesses nacionais, ele mesmo reconhecia a falta de condições para o aparelhamento dessa estrutura quanto a métodos e necessidade de uma rede física de escolas que abrangesse todo o território nacional.

Acontece, no entanto, que essa é uma educação ainda a procura dos seus métodos, - se é possível, numa educação com problemas, encontrar-se um método que não seja igualmente problemático. $\mathrm{O}$ fato é que os métodos tradicionais foram posto de lado e que ainda não foram encontrados os novos métodos. Estamos diante do problema de como tratar satisfatoriamente não problemas definidos, mas simplesmente problemas de que não podemos antecipar os termos ou prever a configuração dos elementos. Esta só pode ser, evidentemente, a educação do futuro e para o futuro (CAMPOS, 1940, p. 4).

Dentre as muitas facetas da educação, neste período de intensa movimentação política que antecedeu à Ditadura Militar, a mais representativa - seja pela ampla circulação no meio político, seja pela defesa de ideais como autonomia e liberdade-, foi o movimento conhecido como Escola Nova.

A Escola Nova estabeleceu-se no centro da polêmica gerada pela sua defesa de uma educação laica em uma sociedade em que a educação era praticamente assunto das ordens religiosas, apoiadas pela robusta elite católica. Suas iniciativas renovadoras, todavia, eram muito exigentes quanto à estrutura física da rede escolar e da formação de professores, o que a tornou uma influência muito mais restrita ao âmbito do discurso, do que de uma efetiva renovação - para usar o termo com o qual ela mesma se designava.

Sua defesa da obrigatoriedade e da gratuidade do ensino constituiu, num mesmo movimento, a propagação de ideais de liberdade e o pertencimento aos ideais de governo e dominação das elites políticas.

Vê-se então, em torno desse esforço para o desenvolvimento das capacidades e do interesse de cada um, a necessidade de uma estrutura tanto física, que exigia uma cara remodelação e aparelhamento das escolas, quanto da difusão das ciências pedagógicas auxiliares a essa abordagem científica da educação escolar: a Biologia Educacional, a História da Educação, a Pedagogia Experimental, a Sociologia Educacional e, especialmente, a Psicologia, desdobrada em denominações tais como Psicologia do Desenvolvimento, Psicologia Educacional e Psicologia das Vocações (CORRÊA, 2006, p. 63).

Um conjunto de artifícios pedagógicos resultaram no "jogo das forças convergentes ao fortalecimento do Estado" (CORRÊA, 2006, p. 64) e à noção de cultura nacional. A presença do poder uniformizador representa um "conjunto de ações que ligam, num mesmo movimento, existência autônoma e pertencimento à ordem científico-político-pedagógica do Estado" (CORRÊA, 2006, p. 63-64). Essas marcas deixadas pela tentativa humanizadora do movimento Escolanovista no Brasil, são atravessadas pelo contexto político e militar das demais nações e, agora "movimenta-se num fluxo capaz de fazer acontecer do fascismo à social democracia - para não dizer do sonho do socialismo estatal, uma assombrosa ditadura militar" (CORREAA, 2006, p. 68). 
Com o término da Segunda Guerra Mundial, que durou do ano de 1939 até 1945, houve, no cenário internacional, uma grande ênfase nos processos de industrialização e de interesse dos países no aprimoramento das estratégias de defesa, pela via dos segredos tecnológicos e militares. O Sputnik 1, satélite lançado pela antiga União Soviética, no ano de 1957, só foi possível pela iniciativa governamental de implementação de um currículo escolar único, que selecionasse as ditas melhores mentes do sistema escolar da época. Num período de dez anos de planejamento, preparação e implementação, entrou em ação, na antiga União Soviética, um currículo que deu ênfase e estabeleceu as disciplinas de Física, Química, Biologia e Matemática, como as mais importantes para a defesa do Estado. Tratava-se de uma corrida espacial que se instalava à propósito da Guerra Fria (1947-1953), na qual Estados Unidos e União Soviética tinham por intuito o melhoramento de arsenais militares.

Segundo Lima (1969, p. 137) "Em toda parte, a prática pedagógica oscila ao sabor das doutrinas e das correntes de opinião (nos EUA, o esputinique soviético provocou uma revolução pedagógica)", assim, percebe-se, uma forte relação das práticas pedagógicas com os acontecimentos políticos e econômicos, principalmente nos EUA. "O índice de adoção de inovações, em escolas públicas de Nova York por exemplo, mais do que dobrou nos quinze meses seguintes ao lançamento do Sputnik" (PFEIFFER, 1915, p. 8). É nesse cenário em que se percebe a educação "medida em dólares e centavos, com a conclusão de que a ampliação e o aperfeiçoamento do ensino compensariam, porque se tratava do meio mais eficaz de elevar a produtividade no país" (PFEIFFER, 1915, p. 9). A compensação econômica, oriunda de processos educacionais de massa, traçou novos horizontes para o Estado e seus planejamentos estratégicos. A noção de defesa-ataque gerou planejamentos e fortes investimentos no sistema de escolarização, tendo em vista as estratégias político-militares dos órgãos de defesa. Em todo globo percebeu-se essas operações, tendo em vista a interferência norte-americana em diversos países, principalmente na América Latina e seus vários experimentos ditatoriais.

Em consonância com as modificações econômicas vinculadas a iniciativas estratégicomilitares que marcaram a emergência da Guerra Fria, o Brasil inicia a Ditadura Militar (19641985) sob o signo do desenvolvimentismo. Vários setores estratégicos são alvo de grande investimento econômico e de propaganda: agricultura, indústria farmacêutica, medicina, indústria armamentista, engenharia, urbanismo, etc. A educação tem, aí, lugar de destaque na medida em que envolve a formação de todo e qualquer habitante no território nacional. É nessa grande movimentação econômica, política e psicossocial, que a Química se instaura juntamente com a Física e Biologia como ciência para formação das massas.

A educação tomada como importante fator nas estratégias psicossociais enfatizadas pela Política de Segurança Nacional ${ }^{8}$ do Período Militar, era justificada por sua capacidade de qualificar a força de trabalho e de consumo, estendida a amplos setores da população. Isso fez surgir uma crucial justificativa em nível de propaganda do Ensino de Ciências para todos. Nesse contexto, o Brasil, sob influência das iniciativas curriculares dos Estados Unidos da América (EUA), também se preocupou em projetar suas ações com base nos planos norte-americanos, nas décadas de 1960 e 1970, buscando, através da implementação desses projetos, encontrar as mais capacitadas "mentes" para aprimorar estratégias de cunho militar - acordos MEC/USAID (Ministério da Educação - MEC e United States Agency for International Development USAID). Esses acordos foram cruciais e influenciam diretamente na noção de educaçãoescolarizada que existe hoje no Brasil e também fora dele.

Esse movimento para instauração de um Projeto de Educação para o país, através da escolarização, esclarece ao final da Ditadura Militar que,

\footnotetext{
${ }^{8}$ Sobre a relação entre a emergência de uma rede nacional de escolas voltada para a educação de todos os brasileiros e a política de Segurança Nacional cf. GONÇALVES, 2011.
} 
Há quem se alarme com a súbita e recente reviravolta ideológica do "sistema" escolar brasileiro que vai, segundo dizem [e ao que tudo indica], do humanismo clássico para radical "profissionalização" [com suas primeiras manifestações na Escola Nova]. Contudo, nada mais tradicional em nossa estória da educação que este pragmatismo: não esqueçamos que fomos sempre um "país de trabalhadores" tão caracteristicamente voltados para a produção que o nosso próprio nome gentílico ("brasileiro" - cortador de pau brasil) é o nome de um profissional (pedreiro, ferreiro, bombeiro). (LIMA, 1969, p. 41).

Durante a Ditadura Militar aconteceu uma série de iniciativas a fim de propagar e divulgar o desenvolvimento das Ciências Naturais, principalmente a Química. Várias obras de divulgação científica voltadas basicamente a jovens e educadores foram publicadas, sendo algumas delas: O Futuro já começou (JUNGK, 1962); O átomo: princípios fundamentais da ciência atômica explicados para o cidadão da era atômica (KAHN, 1964); A matéria (LAPP, 1968); A Química Cria Novo Mundo (JAFFE, 1963).

É nessa perspectiva, ao final da Ditadura Militar no Brasil, que se estabelece um Ensino de Química mais aproximado ao que se conhece nos dias atuais. Um ensino voltado para atender à demanda do mercado tecnológico-científico-estratégico-militar, acompanhado de um discurso de exercício da educação Química focada na cidadania e o trabalho.

Aí está um esboço das principais forças que concorreram para o estabelecimento da Química como ciência objeto de estudo das massas.

Desde os primeiros e esparsos indícios de um interesse científico na educação, manifestados pelos Jesuítas, essa história das Ciências Naturais, com ênfase na emergência da Química como disciplina obrigatória para todos, atravessou praticamente toda a História do Brasil e apresenta inúmeras procedências, entre as quais, se destacam os interesses econômicos dos governos, seus interesses de defesa e sua intrincada história econômica, marcada por interesses corporativos que atravessam e sobrepassam o que veio a se constituir como um planeta dividido em países de constituição Estatal.

A vinda da Família Real para o Brasil marcou o início de um novo modo de interesse científico não mais restrito à curiosidade individual e ao gênio, que caracterizou as poucos iniciativas de estudo das ciências realizadas anteriormente. O iluminismo do Marquês de Pombal propunha um desenvolvimento científico como indispensável para a concorrência econômica de Portugal junto, aos demais países Europeus. Desde aí, com maior ou menor ênfase, as Ciências Naturais e seu desenvolvimento jamais deixaram de ser assunto de interesse político e econômico de qualquer forma de governo em vigência no Brasil.

Desse modo, a linha de forças e influências que resultou no oferecimento dos conteúdos de Química para todo jovem brasileiro, de maneira obrigatória, pela via da escolarização, foi tomando corpo e substância. Do interesse romântico do Imperador pelas Ciências Naturais, passando pela multiplicidade de produções das duas grandes guerras (de mortos a inimagináveis avanços tecnológicos) e chegando à realização da ideologia do progresso do período ditatorial, a Química, como argumento educacional, adquiriu um espaço garantido nos interesses de Estado e na vida de qualquer um de nós.

Um ponto ainda obscuro dessa linha, diz respeito ao surgimento do pelotão de professores de Química, necessários para suprir as exigências de Ensino de Química para todo jovem brasileiro no Ensino Médio. O dia 11 de agosto de 1971 marcou a promulgação da Lei 5.692 e,

\footnotetext{
${ }^{9}$ A obra A Química Cria Novo Mundo (JAFFE, 1963), é um exemplo da emergente ciência atômica em função de suas realizações tanto científicas quanto bélicas.
} 
com ela, a obrigatoriedade do Ensino de Química em todas as escolas de Ensino Médio. De onde e por meio de que estratégias foi possível dispor de professores de Química para todas as escolas de Ensino Médio do país?

\section{Cada um}

Não se pretende aqui, contar a história da Formação de Professores no Brasil, nem uma análise em extensão e profundidade da mesma. O recurso de que lançamos mão é o da ficção. É com ele que pretendemos fazer aparecer uma tênue fibra que compõe a extensa linha da Formação de Professores de Química no Brasil e que, imaginamos, pode apresentar direções e modos para se pensar a mecânica da maquinaria escolar no Brasil contemporâneo.

\subsection{Uma história como qualquer outra de formação de professores}

O dia da minha formatura como Licenciada em Química foi de muita alegria. Ele representou para mim um ponto de chegada: o final do curso universitário. Parecia, realmente, um final. A chegada de uma posição muito esperada e para qual fiz muito esforço. Eu tinha 21 anos e esse dia "encerrava" uma trajetória escolar de mais de 16 anos. Minha formação como professora de Química é devedora de todo trabalho escolar que antecedeu minha entrada no curso de Licenciatura em Química.

Poucas lembranças guardo dos primeiros anos de escola, talvez outros acontecimentos da vida tenham sido mais fortes e marcantes do que o cotidiano da escola e sua regularidade. Desse tempo guardo alguns retalhos esparsos de lembranças, como o coleguinha que fez cocô nas calças, pois queria ir ao banheiro quando "não era a hora de ir". Alguma situação boba do Ensino Fundamental é o trabalho que envolvia colher plantas, folhas e frutos e sua classificação em folhas de papel. Na minha pastinha se encontravam vários tipos de plantas e ao recordá-la desprenderam-se palavras como monocotiledônea, dicotiledônea, pistilo, caule, cálice... Além disso, fica a rotina de ser avaliada, a disciplina rígida.

A entrada no Ensino Médio marcou uma adequação mais acentuada a disciplina das aulas e o estudo mais concentrado. Já me sentia avaliada, e todos me cobravam, pensamentos se revoltavam dentro de mim: o vestibular está chegando! O que eu quero fazer da minha vida? Ser médica, farmacêutica, jornalista? E se eu não passar? E se só eu não passar? E se eu passar e não tiver condições para me manter em outra cidade? As tonalidades brilhantes dos anos de Ensino Fundamental foram ficando para trás e a atmosfera começou a corresponder à sombra da ideia do vestibular e tudo que seria necessária para o ingresso na universidade.

Todos os esforços eram, agora, destinados à obtenção de notas para corresponder a um objetivo que parecia meu, mas que hoje percebo que era também dos meus pais, dos meus professores, dos colegas (e com esses eu competia). Daí estudar treze diferentes disciplinas durante o dia no colégio e a noite viagem para a cidade vizinha para fazer cursinho preparatório para o vestibular. Para isso abandonei tudo que eu mais gostava.

Ao final desse longo percurso prestei vestibular para várias universidades. Como resultado fui aprovada em vários cursos: Licenciatura em Física, Licenciatura em Química, Farmácia e Engenharia Química. A escolha de qual graduação iria cursar foi resultado de dois fatores importantes: proximidade do curso da minha cidade natal e gastos com hospedagem e alimentação. Como o curso de Licenciatura em Química se enquadrava nesses dois pontos, acabei optando pelo ingresso no mesmo.

Agora matriculada nesse curso, extensa eram as disciplinas que se colocavam a minha frente, agora com mais pré-requisitos do que em todo o Ensino Médio: Química Geral I e II; 
Química Analítica Qualitativa e Experimental I e II; Química Analítica Quantitativa e Experimental I e II; Cálculo I e Cálculo II; Física I e Física II; Química Orgânica e Experimental I e II; Química Inorgânica e Experimental I e II; Físico-Química I e II; Físico-Química Experimental; Química Biológica I e II; Toxicologia; Introdução à Biologia; Matemática para o Ensino de Química. As disciplinas de caráter pedagógico iam sendo incorporadas a grade curricular do curso, como se fossem um apêndice dos saberes necessários ao químico, hora licenciado: Psicologia da Educação; Práticas Pedagógicas I ao VII; Estágios Curriculares; Metodologia do Ensino; Libras I e II; Didática; etc.

Vêm-me à mente as primeiras provas, as temidas avaliações de Química Geral e Experimental I, onde precisei rever toda minha forma de estudar do Ensino Médio, isso porque não obtive uma nota satisfatória na primeira prova. Ainda mais eu, que sempre fui uma excelente aluna, que não sabia lidar com a angústia de não ser mais a melhor e não ter as melhores notas. Parece que foi ontem que precisava estudar horas e mais horas aquelas integrais por partes e derivadas que eram exigidas pela professora de Matemática para o Ensino de Química. Embora esse primeiro momento tenha me causado receio, com o passar das provas comecei a tirar excelentes notas.

Com a proximidade dos estágios supervisionados no Ensino Fundamental e no Ensino Médio encontrava-me muito preocupada e ansiosa com o que iria encontrar em sala de aula e como eu iria reagir à nova postura "agora de professora". Durante as disciplinas de Práticas Pedagógicas que tinha na graduação a professora responsável utilizava de artigos e revisões bibliográficas como estratégia para nos aproximar do que poderia ser encontrado durante os estágios. A construção de planos de aula, relatórios e resenhas tomavam considerável tempo das aulas e tinham como finalidade avaliar se eu estava preparada para elaborar e ministrar aulas de Química.

O estágio no Ensino Fundamental realizado em uma turma de $8^{\text {a }}$ série foi acessível para que eu desenvolvesse os planejamentos e as estratégias de ensino, isso porque os conteúdos programáticos destinados para essa turma eram referentes à Tabela Periódica, Semelhança atômica e Ligações Químicas. Minha opção em desenvolver o estágio nessa série esteve relacionada com o domínio dos conhecimentos que eu tinha de Química para tal, tendo em vista que as demais séries do Ensino de Ciências para o Ensino Fundamental tinham maior relação com os conhecimentos de Biologia (os quais eu não dominava). Do mesmo modo, o estágio no Ensino Médio realizado em uma turma do $3^{\circ}$ ano, me exigia o entendimento de conceitos básicos de Química Orgânica (nomenclatura, funções, etc.), nesse sentido não apresentei nenhuma dificuldade para que abordasse os referidos temas. Todavia, o que vale destacar é a forte exigência, em ambos os estágios, por parte dos professores responsáveis pela disciplina da graduação, para que eu elaborasse um plano de aula, para cada hora/aula que realizava. Logo no estágio do Ensino Médio, como ministrei 30 horas/aula, precisei construir 30 planos de aula diferentes.

Mesmo após todas as exigências dos estágios, as provas extensas, trabalhos e atividades durante a graduação, concluí com muita alegria e sensação de dever cumprido minha faculdade de Licenciatura em Química. Foi, naquele instante, o término de uma trajetória de longos quatro anos e meio de estudo para que me tornasse professora de Química. Agora professora formada tenho habilitação para orientar um trabalho com Ciências nos anos finais do Ensino Fundamental e Química no Ensino Médio.

Já com meu diploma em mãos não me recordo de nenhuma aula de Ciências que tenha vivenciado durante minha graduação, mas tenho a habilitação para desenvolver esse trabalho com os alunos. Minha referência de saberes e conteúdos de Ciências para trabalhar no Ensino Fundamental estão, esparsos, lá na minha Educação Básica. Por isso, pego-me pensando será que eu enquanto professora vou produzir nos meus alunos o mesmo efeito de não lembrar, praticamente nada das aulas de Ciências que a minha professora me dava? 
Quando ingressei na Licenciatura em Química imaginei um professor de Química enquanto aquele capaz de olhar para o mundo, coisas, fenômenos e acontecimentos do dia-adia pelo viés da Química. Pensei eu que o professor de Química conseguiria intervir em diferentes situações que exigissem um conhecimento químico, mas percebo que eu enquanto professora, não consigo fazer isso. Quando as crianças me perguntam: Como se formam as nuvens? Porque nós peidamos? Existem extraterrestres? O que é a bomba atômica? Como se faz uma bomba? Eu fico impressionada e não consigo, nem na melhor das hipóteses, me mover para entender e problematizar esses questionamentos. Será que eu nunca terei segurança suficiente para problematizar situações educacionais, além de resolver extensas listas de exercícios com os alunos como preparação para as provas e exames? Será que eu estou condenada a fazer com os outros, o que fizeram comigo? Será que ser professora de Química é só ensinar os alunos a resolver questões? Será que eu sou o agente daquela mesma sombra dos meus professores da Educação Básica?

\section{Todos e cada um}

O panorama genealógico das linhas de forças que configuram o aparecimento dos cursos de Formação de Professores no Brasil inicia com os padres da Companhia de Jesus e sua visão da educação como catequese e formação religiosa, e se estende até a Ditadura Militar e seu interesse desenvolvimentista no qual a educação compunha o rol das estratégias psicossociais concorrentes para a garantia da Segurança Nacional. A emergência do Ensino de Química nas escolas é devedora do empenho de homens como Marquês de Pombal (e sua institucionalização do Iluminismo), Dom Pedro II (e sua paixão pelas Ciências Naturais) e Francisco Campos (e suas certezas fascistas), que concorreram para que a Química tivesse destaque na composição da tessitura do que veio a se tornar o projeto de Escolas para todos no Brasil.

O Ensino de Química teve um importante papel estratégico no campo educacional devido a sua relevância em decisões econômicas, sociais e militares de todos os países considerados desenvolvidos, países que forneceram o modelo de desenvolvimento adotado pelo Brasil. Assim, uma Genealogia da Formação de Professores, no Brasil, pelo viés Ensino de Química, permite perceber a composição de forças e suas múltiplas proveniências. $\mathrm{O}$ trabalho genealógico encontra seu sentido na medida em que se apresenta como 'história do presente'. A analítica aqui proposta teve como preocupação compor num mesmo plano as linhas molares, imensas e múltiplas da história e a linha molecular, pequena, particular do processo de subjetivação envolvido na formação de um professor (qualquer professor) na atualidade.

É possível perceber, com isso, o modo como operam os processos de subjetivação envolvidos no tratamento dispensado pelo sistema educacional e seu costume de formar profissionais para o mercado de trabalho: o trabalho reduzido a trabalho assalariado enquadrado na relação patrão-empregado. A Formação de Professores aparece, então, diferentemente da imagem que a associa a uma trajetória de formação pela via do cumprimento de uma sequência de disciplinas, como uma imensa máquina de subjetivação que responde a uma infinidade de forças. Forças tão múltiplas quanto a guerra e suas tecnologias, os interesses dos Estados manifestados em programas e campanhas, os ideais de paz e progresso, a crença na modificabilidade das crianças convergindo em cidadãos, o medo de ficar abaixo da média e reprovar, o orgulho de ser o primeiro da turma, o constrangimento de fazer xixi na calça quando ainda não era hora de ir ao banheiro.

É sempre pelas forças que atingem o corpo que podemos ser transformados ou modificados. Assim, a produção de uma nação e seu povo em harmonia depende de programas, campanhas e uma capacidade de atingir a todos. Â educação escolar é dada essa tarefa de 
produzir um povo. Ela faz convergir as forças materializadas em exercícios, coerções e figuras que moldam cada um de nós segundo a forma subjetiva do cidadão comum. É na escola que se processa a individualização mais extrema cujo efeito é nossa indiferenciação em meio a todos. Modificar cada um segundo o mesmo processo para todos.

\section{Referências}

ALMEIDA, J. R. P. de. Instrução pública no Brasil (1500-1889). São Paulo: EDUC, 2000.

CAMPOS, F. O Estado Nacional: sua estrutura, seu conteúdo ideológico. Rio de Janeiro: Livraria José Olympio Editora, 1940.

CORRÊA, G. C. Educação, comunicação, anarquia: procedências da sociedade de controle no Brasil. São Paulo: Cortez, 2006.

CORRÊA, G. C. EJA, educação e escolarização. In: ANPED Sul, 10, 2014. Anais da X Reunião Científica da ANPED, Florianópolis, Universidade do Estado de Santa Catarina (UDESC), 2014, p. 01-12.

FERRAZ, M. H. M. As ciências em Portugal e no Brasil (1772-1822): o texto conflituoso da química. São Paulo: EDUC, 1997.

FILGUEIRAS, C. A. L. D. Pedro II e a Química. Revista Química Nova, São Paulo, v. 11, n. 2, p. 210-214, set./nov. 1988.

FOUCAULT, M. Microfísica do poder. Rio de Janeiro: Graal, 1979.

GONÇALVES, N. G. Doutrina de Segurança Nacional e Desenvolvimento na Ditadura CivilMilitar: Estratégias e a Educação. In: XXVI SIMPÓSIO NACIONAL DE HISTÓRIA, 2011, São Paulo. Anais do XXVI Simpósio Nacional de História São Paulo, Universidade de São Paulo (USP), 2011, p. 1-17.

JAFFE, B. A química cria novo mundo. Rio de Janeiro: Centro de Publicações Técnicas da Aliança para o Progresso, 1963.

JUNGK, R. O Futuro já começou. São Paulo, SP: Editora Melhoramentos, 1962.

KAHN, F. $O$ átomo: princípios fundamentais da ciência atômica explicados para o cidadão da era atômica. 7. ed. São Paulo, SP: Melhoramentos, 1964.

LAPP, R. E. A matéria. Rio de Janeiro: Livraria Jose Olympio, 1968.

LIMA, L. de O. Estórias da educação no Brasil: de Pombal a Passarinho. Rio de Janeiro: Brasília, 1969. (Coleção Pedagogia).

KRASILCHIK, M. O professor e o currículo das ciências. São Paulo: Edusp, 1987. 
PFEIFFER, J. E. Uma visão nova da Educação: "Systems analysis", ou análise de sistemas em nossas escolas e faculdades. São Paulo: Companhia Editora Nacional/Edusp, 1971.

REIMER, E. A Escola está morta: alternativas em educação. Rio de Janeiro: Livraria Francisco Alves, 1983. 